\title{
BMP-6 protects retinal pigment epithelial cells from oxidative stress-induced injury by inhibiting the MAPK signaling pathways
}

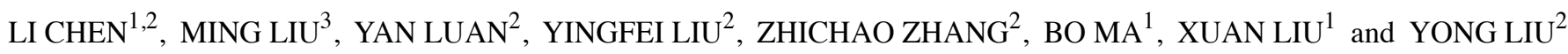 \\ ${ }^{1}$ Department of Ophthalmology, The First Affiliated Hospital of Xi'an Jiaotong University; \\ ${ }^{2}$ Institute of Neurobiology, Xi'an Jiaotong University Health Science Center, Xi'an, Shaanxi 710061; \\ ${ }^{3}$ Department of Ophthalmology, The First Hospital of Xi'an, Xi'an, Shaanxi 710002, P.R. China
}

Received December 3, 2017; Accepted May 10, 2018

DOI: $10.3892 /$ ijmm.2018.3675

\begin{abstract}
Worldwide, neovascular age-related macular degeneration (nAMD) is one of the most common causes of blindness in the elderly. In particular, degeneration of retinal pigment epithelial (RPE) cells represents the main pathological process in the development of nAMD, and oxidative stress serves a major role. The present study aimed to investigate the association between bone morphogenetic protein 6 (BMP-6) and nAMD. BMP-6 concentration was significantly reduced in patients with wet nAMD compared with in the control group. Furthermore, the present study investigated the protective effects of BMP-6 on RPE cells following oxidative stress-induced injury. Cell Counting Kit- 8 assay and terminal deoxynucleotidyl transferase dUTP nick-end labeling staining demonstrated that BMP-6 increased RPE cell viability, which was decreased following treatment with hydrogen peroxide $\left(\mathrm{H}_{2} \mathrm{O}_{2}\right)$, and reduced $\mathrm{H}_{2} \mathrm{O}_{2}$-induced apoptosis. In addition, western blotting revealed that BMP-6 reversed the decrease in pro-caspase-3 levels and the dysregulation of the B-cell lymphoma 2 (Bcl-2)/Bcl-2-associated X protein (Bax) balance caused by $\mathrm{H}_{2} \mathrm{O}_{2}$. In addition, alterations in c-Jun N-terminal protein kinase $(\mathrm{JNK})$ and p38 mitogen-activated protein kinase (MAPK) expression were examined, and pretreatment with BMP- 6 was demonstrated to reduce $\mathrm{H}_{2} \mathrm{O}_{2}$-induced activation of JNK and p38 MAPK. Conversely, the effects of BMP-6 were attenuated by its inhibitor noggin. In conclusion, the
\end{abstract}

Correspondence to: Professor Yong Liu, Institute of Neurobiology, Xi'an Jiaotong University Health Science Center, 76 Yanta West Road, Xi'an, Shaanxi 710061, P.R. China

E-mail: liuy5599@163.com

Abbreviations: nAMD, neovascular age-related macular degeneration; BMP-6, bone morphogenetic protein 6; RPE, retinal pigment epithelial; $\mathrm{H}_{2} \mathrm{O}_{2}$, hydrogen peroxide; JNK, c-Jun N-terminal protein kinase; MAPK, mitogen-activated protein kinase; Bcl-2, B-cell lymphoma 2; Bax, Bcl-2-associated $\mathrm{X}$ protein

Key words: neovascular age-related macular degeneration, bone morphogenetic protein 6 , oxidative stress, retinal pigment epithelial cells, apoptosis present study demonstrated that BMP- 6 may protect RPE cells from oxidative stress injury to a certain extent, which may be associated with alterations in the MAPK signaling pathway. However, the specific mechanism of action underlying this effect requires further investigation. Overall, the present study laid a foundation for exploring novel nAMD treatment methods.

\section{Introduction}

Neovascular age-related macular degeneration (nAMD) may lead to central vision loss and is the leading cause of reduced visual acuity in the elderly worldwide (1). At present, the pathogenesis of nAMD is not completely understood; however, an increasing body of evidence suggests that oxidative stress and iron-induced oxidative stress are major causes of macular degeneration $(2,3)$.

Bone morphogenetic protein 6 (BMP-6) belongs to the transforming growth factor superfamily and may have a critical role in $\mathrm{nAMD}$ pathogenesis. BMPs are expressed in various ocular tissues and serve key roles in eye development and differentiation. Specifically, autopsy results have indicated that BMP-6 levels are significantly decreased in the retinal pigment epithelial (RPE) cells of patients with early AMD (4). Furthermore, BMP-6 knockout mice experience intrahepatic iron accumulation (5), and exhibit age-related iron accumulation and retinal degeneration (6). BMP-6 signaling in hepatocytes is a central transcriptional regulator of the iron-associated hormone hepcidin, which controls the systemic iron balance (7).

At present, the role of BMP-6 in nAMD is poorly understood. To address this issue, the present study measured the aqueous levels of BMP- 6 in patients with nAMD. Furthermore, to the best of our knowledge, the protective effects of BMP-6 on RPE cells have rarely been reported. Therefore, the main objective of the present study was to investigate the role of BMP-6 in protecting RPE cells from oxidative stress injury, and to determine the potential signaling pathways involved in this protection. To this end, hydrogen peroxide $\left(\mathrm{H}_{2} \mathrm{O}_{2}\right)$ was used to induce RPE cell damage and to establish a cell model of oxidative stress injury. Using this model, the present study examined the ability of BMP- 6 pretreatment to protect cells from $\mathrm{H}_{2} \mathrm{O}_{2}$-induced injury. In addition, the BMP-6 inhibitor 
noggin and inhibitors of the relevant signaling pathways were used to identify potential signaling pathways involved in this protection. The present study indicated that BMP- 6 protects RPE cells from oxidative damage by inhibiting the c-Jun $\mathrm{N}$-terminal protein kinase (JNK) and p38 mitogen-activated protein kinase (MAPK) signaling pathways, thereby downregulating pro-caspase- 3 and dysregulating the balance between $\mathrm{B}$-cell lymphoma $2(\mathrm{Bcl}-2)$ and $\mathrm{Bcl}-2$-associated $\mathrm{X}$ protein (Bax) expression.

\section{Materials and methods}

Patients and controls. This prospective cross-sectional study was performed at the Department of Ophthalmology, Xi'an Jiao-tong University (Xi'an, China). A total of 30 patients with untreated nAMD and 20 age- and sex-matched controls undergoing cataract surgery were enrolled in the present study between July 1 and December 31, 2016. The present study was approved by the Ethics Committee of the First Affiliated Hospital of Xi'an Jiao-tong University (Xi'an, China), and patients provided written informed consent. Patients with nAMD were included in the study group if they met the following criteria at their initial visit to the department: Active choroidal neovascularization secondary to AMD, confirmed by spectral domain optical coherence tomography and fluorescein angiography.

Patients were excluded from the study if they met any of the following criteria: Previous treatment for nAMD, including antiangiogenic medications such as bevacizumab, ranibizumab or pegaptanib, laser photocoagulation or vitrectomy; they had diabetes mellitus, diabetic retinopathy or iris rubeosis; they had a history of ocular inflammation and vitreoretinal diseases; and/or they had a recent myocardial infarction, cerebral vascular accident or malignant hypertension. Control subjects were included if they were scheduled to have cataract surgery, did not have a history of hypertension or diabetes mellitus, and had no retinal vascular diseases, as determined by comprehensive ophthalmic examinations by retinal specialists.

Collection of aqueous humor samples. Aqueous humor samples were obtained at the beginning of cataract surgery from the control patients and immediately prior to intravitreal bevacizumab injections from patients with nAMD. All sample collections and intravitreal injections were performed using standard sterile methods. Prior to intravitreal bevacizumab injection or cataract surgery, undiluted aqueous humor samples (0.1-0.2 ml) were obtained by anterior-chamber paracentesis using a 30-gauge needle, with no complications. The samples were placed immediately into safe-lock microcentrifuge tubes $(1.5 \mathrm{ml})$ and were stored at $-80^{\circ} \mathrm{C}$ prior to analysis.

Measurement of BMP-6 levels using ELISA. Aqueous BMP-6 levels were measured by ELISA using a commercially available BMP-6 ELISA kit (\#DY507; R\&D Systems, Inc., Minneapolis, MN, USA), according to the manufacturer's protocol.

In vitro culture of RPE cells. ARPE-19 cells were purchased from the American Type Culture Collection (Manassas, VA, USA), and were cultured in Dulbecco's modified Eagle's medium (DMEM; Gibco; Thermo Fisher Scientific, Inc., Waltham, MA, USA) containing $10 \%$ fetal bovine serum (Gibco; Thermo Fisher Scientific, Inc.) at $37^{\circ} \mathrm{C}$ in an atmosphere containing $5 \% \mathrm{CO}_{2}$ and saturated humidity (Sanyo, Osaka, Japan). The cells were subcultured by trypsinization and were mechanically separated by pipetting, in order to prepare single-cell suspensions.

Experimental interventions. An oxidative stress model was generated via exposure of RPE cells to $\mathrm{H}_{2} \mathrm{O}_{2}$. Briefly, RPE cells were adherently cultured in poly-D-lysine (PDL)-coated 96-well cell culture plates. Subsequently, the RPE cells (5,000 cells/well) were incubated with a series of $\mathrm{H}_{2} \mathrm{O}_{2}$ solutions of various concentrations $(10,50,100,200$ and $500 \mu \mathrm{M})$ for 3,6 and $12 \mathrm{~h}$ at $37^{\circ} \mathrm{C}$. Cell viability was examined using a Cell Counting Kit-8 (CCK-8) assay, in order to determine the appropriate $\mathrm{H}_{2} \mathrm{O}_{2}$ concentration and treatment duration, which were $200 \mu \mathrm{M} \mathrm{H}_{2} \mathrm{O}_{2}$ and $6 \mathrm{~h}$. To evaluate the ability of BMP-6 to protect cells from $\mathrm{H}_{2} \mathrm{O}_{2}$-induced cell damage, $\mathrm{RPE}$ cells were pretreated with various BMP-6 concentrations $(0,1,10,50$, 100 and $200 \mathrm{ng} / \mathrm{ml}$; R\&D Systems, Inc.) for $1 \mathrm{~h}$. Subsequently, the cells were treated with $200 \mu \mathrm{M} \mathrm{H}_{2} \mathrm{O}_{2}$ for $6 \mathrm{~h}$. Cell viability and apoptosis were examined using the CCK- 8 method and terminal deoxynucleotidyl transferase dUTP nick-end labeling (TUNEL) staining, respectively. The expression levels of the apoptotic proteins Bcl-2, Bax and pro-caspase-3 were analyzed by western blotting. In addition, the BMP-6 antagonist noggin (Abcam, Cambridge, UK) was used to assess the ability of BMP-6 to protect RPE cells. Specifically, $3 \mu \mathrm{g} / \mathrm{ml}$ noggin was added to the culture medium, and BMP-6 $(100 \mathrm{ng} / \mathrm{ml})$ was added to the culture medium after $1 \mathrm{~h}$. After BMP-6 treatment for $1 \mathrm{~h}, 200 \mu \mathrm{M} \mathrm{H}_{2} \mathrm{O}_{2}$ was added. Following $6 \mathrm{~h}$ of $\mathrm{H}_{2} \mathrm{O}_{2}$ treatment, TUNEL staining was performed to analyze the apoptotic status of the cell groups. To examine the role of JNK and p38 MAPK signaling in BMP-6-mediated protection of oxidative stress-injured RPE cells, the cells were pretreated with the p38-specific antagonist SB203580 $(10 \mu \mathrm{M}$; Sigma-Aldrich; Merck KGaA, Darmstadt, Germany), the JNK-specific antagonist SP600125 (10 $\mu \mathrm{M}$; Sigma-Aldrich; Merck KGaA), BMP-6 (100 ng/ml) or an equal volume of normal saline for $1 \mathrm{~h}$. Subsequently, $200 \mu \mathrm{M} \mathrm{H}_{2} \mathrm{O}_{2}$ was added to all groups, with the exception of the control group. After $6 \mathrm{~h}$ of $\mathrm{H}_{2} \mathrm{O}_{2}$ treatment, p38 and JNK expression were measured by western blotting. All experiments were repeated three times.

Measurement of cell viability. The viability of ARPE-19 cells was measured using the CCK-8 assay kit (Sigma-Aldrich; Merck KGaA). Briefly, RPE cells were seeded into 96-well plates at a density of $1 \times 10^{4}$ cells/well. After overnight adherent growth, the cells were divided into the various experimental groups, and were treated and incubated accordingly. Subsequently, CCK-8 reagent was added to all wells containing cells, and the cells were incubated at $37^{\circ} \mathrm{C}$ for $2 \mathrm{~h}$. The absorbance was measured at $450 \mathrm{~nm}$ using a microplate reader (Model EL800; Bio-Tek Instruments, Inc., Winooski, VT, USA), and the results were statistically analyzed.

TUNEL staining. The apoptotic rate of RPE cells was measured by TUNEL staining. Briefly, adherent cultured RPE cells were treated according to the experimental requirements, 
and were then fixed in $4 \%$ paraformaldehyde at room temperature for $30 \mathrm{~min}$. Subsequently, cells were washed three times with $0.01 \mathrm{M}$ PBS (5 min/wash) and were stained with TUNEL reagent, according to the manufacturer's protocol. Briefly, at the end of each treatment, the cells were fixed in $4 \%$ paraformaldehyde in PBS for 20 min at room temperature. Following permeabilization using $0.1 \%$ Triton $\mathrm{X}-100$ in $0.1 \%$ sodium citrate for $2 \mathrm{~min}$ on ice, the cells were incubated with $50 \mathrm{ml}$ TUNEL reaction mixture for $1 \mathrm{~h}$ at $37^{\circ} \mathrm{C}$. Cells were further counterstained with DAPI $(1 \mathrm{mg} / \mathrm{ml})$ prior to mounting. After TUNEL staining, the cells were counterstained with DAPI for

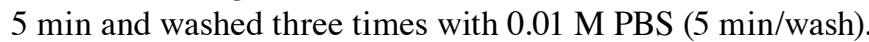
The cells were then mounted with the anti-quenching mounting medium Fluoroshield, after which cells were examined and images were captured under a fluorescence microscope. The TUNEL staining results were statistically analyzed.

Western blot analysis. ARPE-19 cells were seeded into 6 -well plates at a density of $1 \times 10^{6}$ cells/well. Following the relevant treatments, cells were washed with serum-free DMEM and harvested with 10\% FBS-containing DMEM. The protein expression levels of Bcl-2, Bax, pro-caspase-3, p38 MAPK and JNK were examined by western blotting. $\beta$-actin was used as the internal reference. The relative Bcl-2, Bax, pro-caspase-3, p38 MAPK and JNK protein expression levels were calculated and normalized to $\beta$-actin, which was used as an internal control. To extract total proteins, the cells were lysed using tissue lysis buffer [50 mM Tris- $\mathrm{HCl}$ (pH 7.6), $150 \mathrm{mM} \mathrm{NaCl,} 1 \%$ Triton X-100, $1 \mathrm{mM}$ EDTA, $1 \mathrm{mM}$ EGTA, $0.5 \%$ sodium deoxycholate, $0.1 \%$ SDS, $1 \mathrm{mM}$ sodium orthovanadate, $50 \mathrm{mM}$ sodium fluoride, $20 \mathrm{mM} \mathrm{Na}_{4} \mathrm{P}_{2} \mathrm{O}_{7}$ and $10 \%$ glycerol], and the concentrations of the protein samples were determined using the bicinchoninic acid protein quantification assay, based on established standard curves. An equal amount of protein from each sample $(30 \mu \mathrm{g})$ was mixed with loading buffer and denatured by heating at $97^{\circ} \mathrm{C}$ for $6 \mathrm{~min}$. After cooling, the proteins were separated by $12 \%$ SDS-PAGE and were then transferred from the separating gels onto polyvinylidene fluoride (PVDF) membranes using transfer apparatus. The PVDF membranes were blocked with blocking solution [Tris-buffered saline-Tween 20 (TBST) + $50 \mathrm{~g} / 1$ skim milk powder] at room temperature for $30 \mathrm{~min}$, and were then incubated with following primary antibodies: Anti-caspase-3 (1:1,000; \#9662), anti-Bcl-2 (1:1,000; \#3498), anti-Bax (1:1,000; \#2774), anti-phosphorylated (p)-JNK2 (1:2,000; \#4668), anti-JNK2 (1:1,000; \#4672), anti-p-p38 (1:1,000; \#4511), anti-p38 (1:2,000; \#9212) and anti- $\beta$-actin (1:25,00; \#3700) (all Cell Signaling Technology, Inc., Danvers, MA, USA). Subsequently, the membranes were washed three times with $1 \mathrm{X}$ TBST for 15,5 and 5 min successively, and were incubated with appropriately diluted anti-rabbit or anti-mouse immunoglobulin G secondary antibodies (both 1:100,000; \#A0545 and \#A9044; Sigma-Aldrich; Merck $\mathrm{KGaA}$ ) at room temperature for $1 \mathrm{~h}$. The membranes were then washed again with $1 \mathrm{X}$ TBST (three times for 15, 5 and $5 \mathrm{~min}$ ) and developed using an enhanced chemiluminescence kit (Pierce; Thermo Fisher Scientific, Inc.). Western blotting results were semi-quantitatively analyzed using the grayscale feature in ImageJ 3.5 software (National Institutes of
Table I. Comparison between the nAMD and control groups.

\begin{tabular}{lccc}
\hline Variable & nAMD $(\mathrm{n}=30)$ & Control $(\mathrm{n}=20)$ & P-value \\
\hline Age, years & $68.63 \pm 8.63$ & $71.05 \pm 10.73$ & $0.281^{\mathrm{a}}$ \\
Sex (female \%) & $18(60 \%)$ & $9(45 \%)$ & $0.388^{\mathrm{b}}$ \\
Baseline visual & $1.15 \pm 0.80$ & $0.75 \pm 0.43$ & $0.035^{\mathrm{a}}$ \\
acuity, LogMAR & & & \\
IOP, mmHg & $13.70 \pm 2.63$ & $15.05 \pm 3.34$ & $0.182^{\mathrm{a}}$
\end{tabular}

${ }^{a}$ Mann-Whitney U test; ${ }^{b}$ Fisher's exact test. IOP, intraocular pressure; LogMAR, logarithm of the minimum angle of resolution.

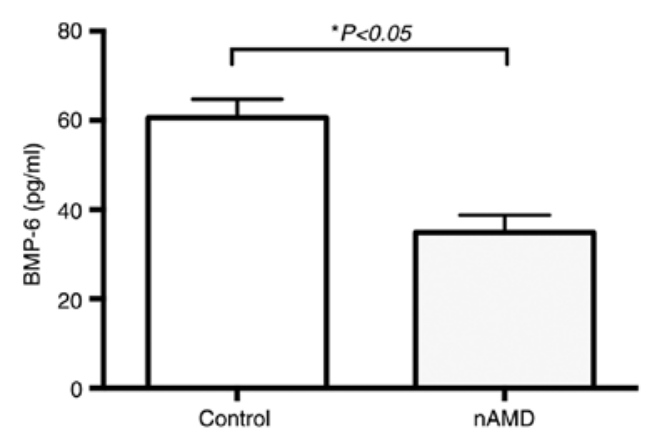

Figure 1. Mean aqueous levels of BMP-6 in the control and nAMD groups The P-values were obtained using independent t-tests. Data are presented as the means \pm standard deviation. ${ }^{*} \mathrm{P}<0.05$. BMP- 6 , bone morphogenetic protein 6; nAMD, neovascular age-related macular degeneration.

Health, Bethesda, MD, USA). Western blotting was repeated three times, and each replicate yielded similar results.

Statistical analysis. Quantitative data are presented as the means \pm standard deviation. Data were analyzed using SPSS 13.0 software (SPSS Inc., Chicago, IL, USA). Differences between the study group and the control group were estimated using a nonparametric Mann-Whitney rank sum test and independent t-test when appropriate. Fisher's exact test was used to compare noncontinuous variables. Cell viability, apoptosis and western blotting data were compared between different groups with one-way analysis of variance followed by Tukey's test. $\mathrm{P}<0.05$ was considered to indicate a statistically significant difference.

\section{Results}

Association between $n A M D$ and aqueous BMP-6 levels. The study population consisted of 30 patients and 20 control subjects. The clinical characteristics of the two groups are summarized in Table I. The nAMD and control groups had a mean age of $68.63 \pm 8.63$ (range, $45-74$ ) and $71.05 \pm 10.73$ (range, 46-75) years, respectively. In addition, 60 (18/30) and $45 \%(9 / 20)$ of patients were female in the nAMD and control groups, respectively. Age and intraocular pressure were normally distributed in both groups. The two groups did not differ significantly in terms of age or sex distribution. The mean aqueous BMP-6 levels were $34.82 \pm 3.91$ and $60.58 \pm 4.21 \mathrm{pg} / \mathrm{ml}$ in the nAMD and control groups, respectively $(\mathrm{P}<0.01$; Fig. 1). 

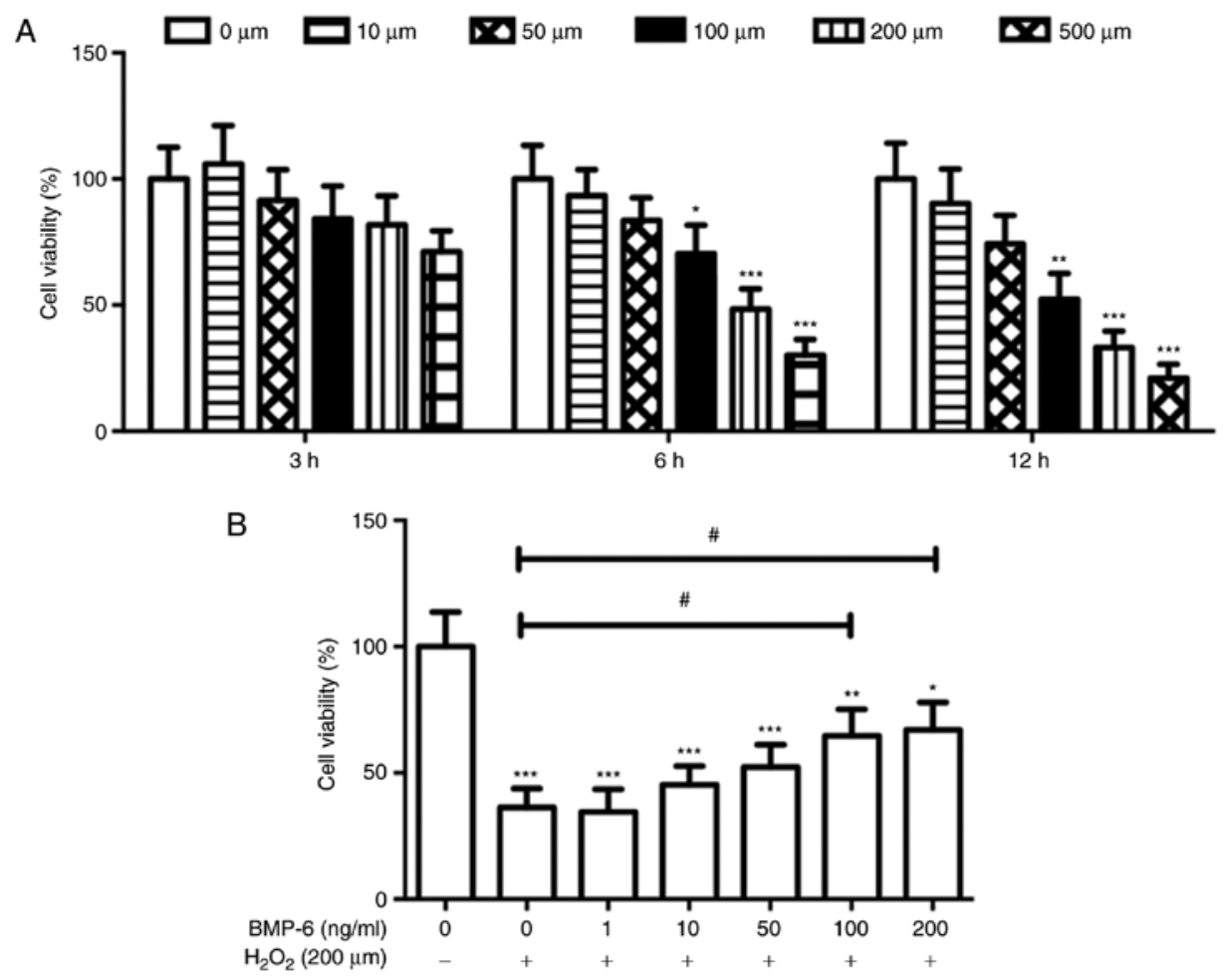

Figure 2. BMP-6 attenuates the $\mathrm{H}_{2} \mathrm{O}_{2}$-induced decrease in RPE cell viability. Cell viability was measured using the CCK-8 assay. (A) Based on examination of the effects of various $\mathrm{H}_{2} \mathrm{O}_{2}$ concentrations on RPE cells, treatment with $200 \mu \mathrm{M} \mathrm{H}_{2} \mathrm{O}_{2}$ for 6 h was selected for subsequent experiments. (B) To evaluate the ability of BMP- 6 to protect cells from $\mathrm{H}_{2} \mathrm{O}_{2}$-induced injury, RPE cells were pretreated with various BMP- 6 concentrations for $1 \mathrm{~h}$ and then exposed to $200 \mu \mathrm{M}$ $\mathrm{H}_{2} \mathrm{O}_{2}$ for $6 \mathrm{~h}$. Cell viability was examined, and the results were statistically analyzed. ${ }^{*} \mathrm{P}<0.05,{ }^{* *} \mathrm{P}<0.01$ and ${ }^{* * * *} \mathrm{P}<0.001$ vs. the blank control group. ${ }^{*} \mathrm{P}<0.01$ vs. cells exposed to $200 \mu \mathrm{M} \mathrm{H}_{2} \mathrm{O}_{2}$ only. BMP-6, bone morphogenetic protein $6 ; \mathrm{H}_{2} \mathrm{O}_{2}$, hydrogen peroxide; RPE, retinal pigment epithelial.

BMP-6 attenuates the $\mathrm{H}_{2} \mathrm{O}_{2}$-induced decrease in $\mathrm{RPE}$ cell viability. In the present study, cultured RPE cells were treated with a specific $\mathrm{H}_{2} \mathrm{O}_{2}$ concentration to establish an RPE cell model of oxidative stress injury. RPE cell viability was inversely correlated with $\mathrm{H}_{2} \mathrm{O}_{2}$ concentration and treatment duration. In particular, treatment with 200 and $500 \mu \mathrm{M}$ $\mathrm{H}_{2} \mathrm{O}_{2}$ for 6 and $12 \mathrm{~h}$ decreased the viability of RPE cells by $>50 \%$ compared with in the control group (Fig. 2A). Based on these results and the requirements of the subsequent experimental treatments, a concentration of $200 \mu \mathrm{M} \mathrm{H}_{2} \mathrm{O}_{2}$ and treatment duration of $6 \mathrm{~h}$ were selected for subsequent experiments. To evaluate the ability of BMP- 6 to protect cells from $\mathrm{H}_{2} \mathrm{O}_{2}$-induced damage, RPE cells were pretreated with various concentrations of BMP-6 (0, 1, 10, 50, 100 and $200 \mathrm{ng} / \mathrm{ml}$ ) for $1 \mathrm{~h}$. Following BMP- 6 treatment, the cells were treated with $200 \mu \mathrm{M} \mathrm{H}_{2} \mathrm{O}_{2}$ for $6 \mathrm{~h}$. Pretreatment with BMP-6 attenuated $\mathrm{H}_{2} \mathrm{O}_{2}$-induced oxidative damage in RPE cells in a concentration-dependent manner (Fig. 2B). Therefore, $100 \mathrm{ng} / \mathrm{ml} \mathrm{BMP-6}$ was selected for subsequent experiments.

Effects of BMP-6 on the expression of apoptotic proteins in RPE cells following $\mathrm{H}_{2} \mathrm{O}_{2}$-mediated oxidative stress injury. Alterations in the expression of apoptosis-related proteins following BMP-6 pretreatment in RPE cells exposed to oxidative stress injury were examined by western blotting. Briefly, the cells were treated with various BMP- 6 concentrations $(0,5,10,50,100$ and $200 \mathrm{ng} / \mathrm{ml})$, and were then subjected to western blotting to analyze the expression levels of pro-caspase-3, Bcl-2 and Bax. Compared with in the blank control group, the protein expression levels of pro-caspase-3 and Bcl-2 were markedly decreased, whereas the protein levels of Bax were significantly increased following treatment with $\mathrm{H}_{2} \mathrm{O}_{2}$. Compared with in cells exposed to $\mathrm{H}_{2} \mathrm{O}_{2}$ only, cells pretreated with various BMP- 6 concentrations and exposed to $200 \mu \mathrm{M} \mathrm{H}_{2} \mathrm{O}_{2}$ exhibited a concentration-dependent increase in pro-caspase- 3 and Bcl-2 protein levels, and a concentration-dependent decrease in Bax protein levels (Fig. 3). These results suggested that pretreatment with BMP-6 may inhibit the activation of apoptosis-associated proteins; thereby protecting RPE cells from oxidative stress injury.

$\mathrm{H}_{2} \mathrm{O}_{2}$-induced apoptosis and the ability of BMP-6 to attenuate $\mathrm{H}_{2} \mathrm{O}_{2}$-induced apoptosis based on TUNEL staining. To confirm that BMP-6 protected RPE cells from $\mathrm{H}_{2} \mathrm{O}_{2}$-induced injury, cells were also treated with the BMP-6 antagonist noggin. Noggin $(3 \mu \mathrm{g} / \mathrm{ml})$ was added to the culture medium and BMP-6 (100 ng/l) was added to the culture medium after $1 \mathrm{~h}$. After $1 \mathrm{~h}$ of BMP-6 treatment, cells were exposed to $200 \mu \mathrm{M} \mathrm{H}_{2} \mathrm{O}_{2}$ for $6 \mathrm{~h}$. TUNEL staining was performed to examine apoptosis in each cell group (Fig. 4). The percentage of TUNEL-positive cells exceeded $50 \%$ in the $200 \mu \mathrm{M} \mathrm{H}_{2} \mathrm{O}_{2}$ group, and was significantly increased compared with the percentage in the control group. The number of TUNEL-positive cells was markedly decreased in the BMP-6 group. Conversely, blocking the effects of BMP-6 using the BMP- 6 antagonist noggin increased the number of TUNEL-positive cells, compared with in the $\mathrm{H}_{2} \mathrm{O}_{2}+$ BMP-6 

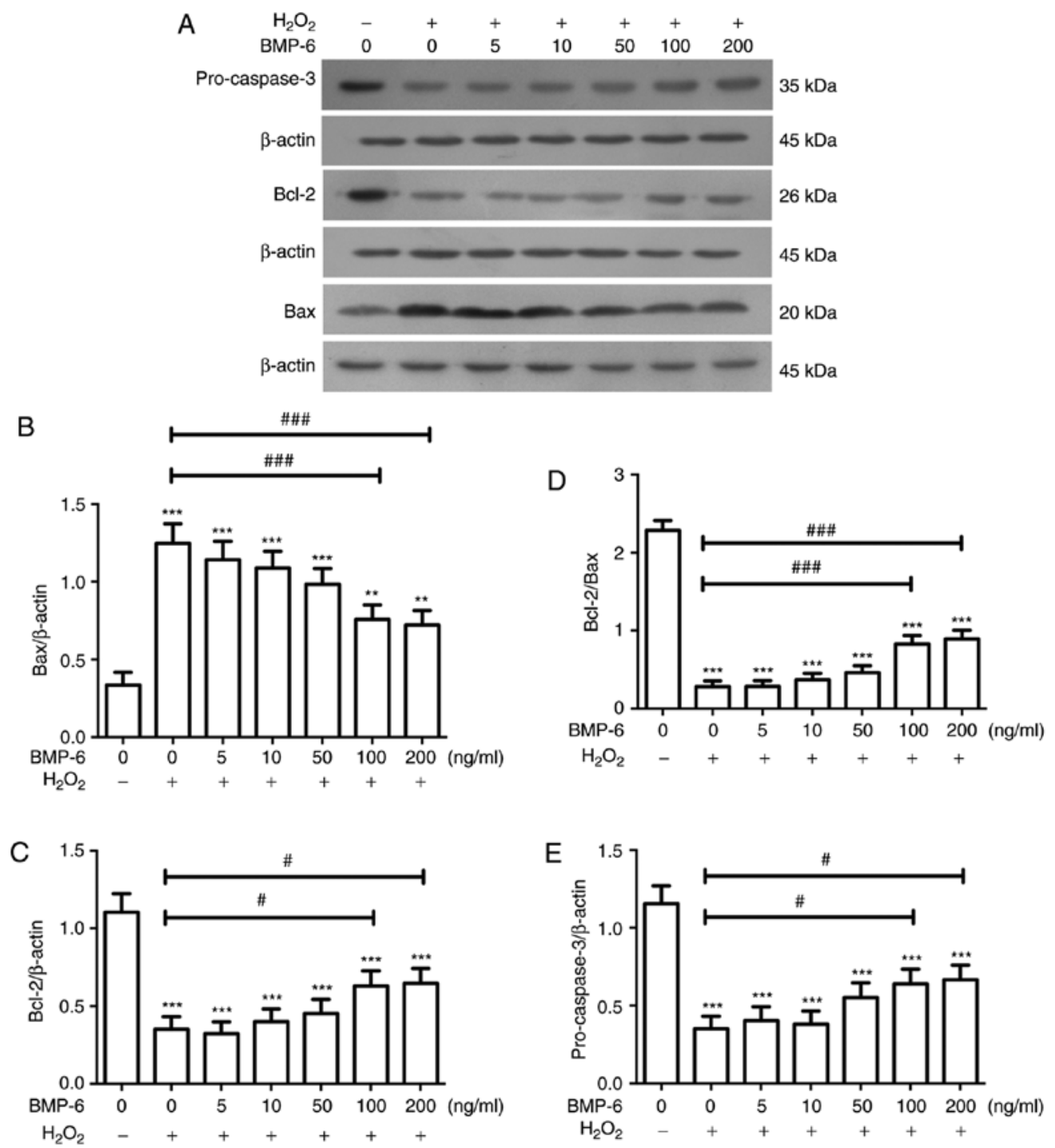

Figure 3. Effects of BMP-6 treatment on the expression levels of apoptotic proteins in RPE cells following $\mathrm{H}_{2} \mathrm{O}_{2}$-mediated oxidative stress injury. (A) Western blot images showing the protein levels of pro-caspase-3, Bcl-2 and Bax; $\beta$-actin was used as an internal reference. (B-E) Expression levels of pro-caspase-3, $\mathrm{Bcl}-2$ and $\mathrm{Bax}$ were normalized to $\beta$-actin, and alterations in the ratio of $\mathrm{Bcl}-2$ to $\mathrm{Bax}$ expression were determined. Data are presented as the means \pm standard deviation. ${ }^{*} \mathrm{P}<0.05,{ }^{* *} \mathrm{P}<0.01$ and ${ }^{* * *} \mathrm{P}<0.001$ vs. the blank control group. ${ }^{\#} \mathrm{P}<0.01,{ }^{\# \#} \mathrm{P}<0.01$ and ${ }^{\# \# \#} \mathrm{P}<0.001$ vs. cells exposed to $200 \mu \mathrm{M} \mathrm{H}_{2} \mathrm{O}_{2}$ only. Bax, Bcl-2-associated X protein; Bcl-2, B-cell lymphoma 2; BMP-6, bone morphogenetic protein 6; $\mathrm{H}_{2} \mathrm{O}_{2}$, hydrogen peroxide; RPE, retinal pigment epithelial.

group (Fig. 4). These findings suggested that BMP-6 may protect RPE cells from $\mathrm{H}_{2} \mathrm{O}_{2}$-induced damage.

BMP-6 protects RPE cells by inhibiting p38 and JNK signaling. To identify the intracellular signaling pathways involved in regulation of the protective effects of BMP-6, the present study examined the JNK and p38 MAPK signaling pathways. Previous studies demonstrated that the JNK and p38 signaling pathways may have key roles in neuroprotection, inflammatory regulation and the oxidative stress response (8-10). RPE cells were treated with various BMP-6 concentrations $(0,1,5,10,50,100$ and $200 \mathrm{ng} / \mathrm{ml})$ for $1 \mathrm{~h}$. All groups were then exposed to $\mathrm{H}_{2} \mathrm{O}_{2}(200 \mu \mathrm{M})$ for $6 \mathrm{~h}$, and proteins were and subjected to western blotting to determine the expression levels of p-p38 and p-JNK2. Compared with in the $\mathrm{H}_{2} \mathrm{O}_{2}$-treated group, BMP- 6 reduced the activity of p-p38 and p-JNK2 in a concentration-dependent manner (Fig. 5A-C). To confirm that BMP-6 inhibited p38 and
JNK2 signaling, cells were treated with noggin. Briefly, noggin was added to the culture medium at a concentration of $3 \mu \mathrm{g} / \mathrm{ml}$. After $1 \mathrm{~h}$, BMP-6 $(100 \mathrm{ng} / \mathrm{ml})$ was added to the culture medium for $1 \mathrm{~h}$. Subsequently, $200 \mu \mathrm{M} \mathrm{H}_{2} \mathrm{O}_{2}$ was added to the culture medium. After $6 \mathrm{~h}$ of $\mathrm{H}_{2} \mathrm{O}_{2}$ treatment, western blotting was performed to examine p38 and JNK2 phosphorylation levels. The results demonstrated that noggin suppressed BMP-6-mediated inhibition of p38 and JNK2 activity (Fig. 5D-F).

Confirmation that BMP-6 affects the p38 and JNK pathways. The present study indicated that $\mathrm{H}_{2} \mathrm{O}_{2}$ may activate the $\mathrm{p} 38$ and JNK pathways, whereas BMP-6 inhibited these pathways. These findings suggested that BMP-6 may exert its protective effect by inhibiting the activities of the p38 and JNK pathways. Subsequently, the present study examined whether p38 and JNK inhibition could protect RPE cells against $\mathrm{H}_{2} \mathrm{O}_{2}$-mediated oxidative stress injury. Compared with in 

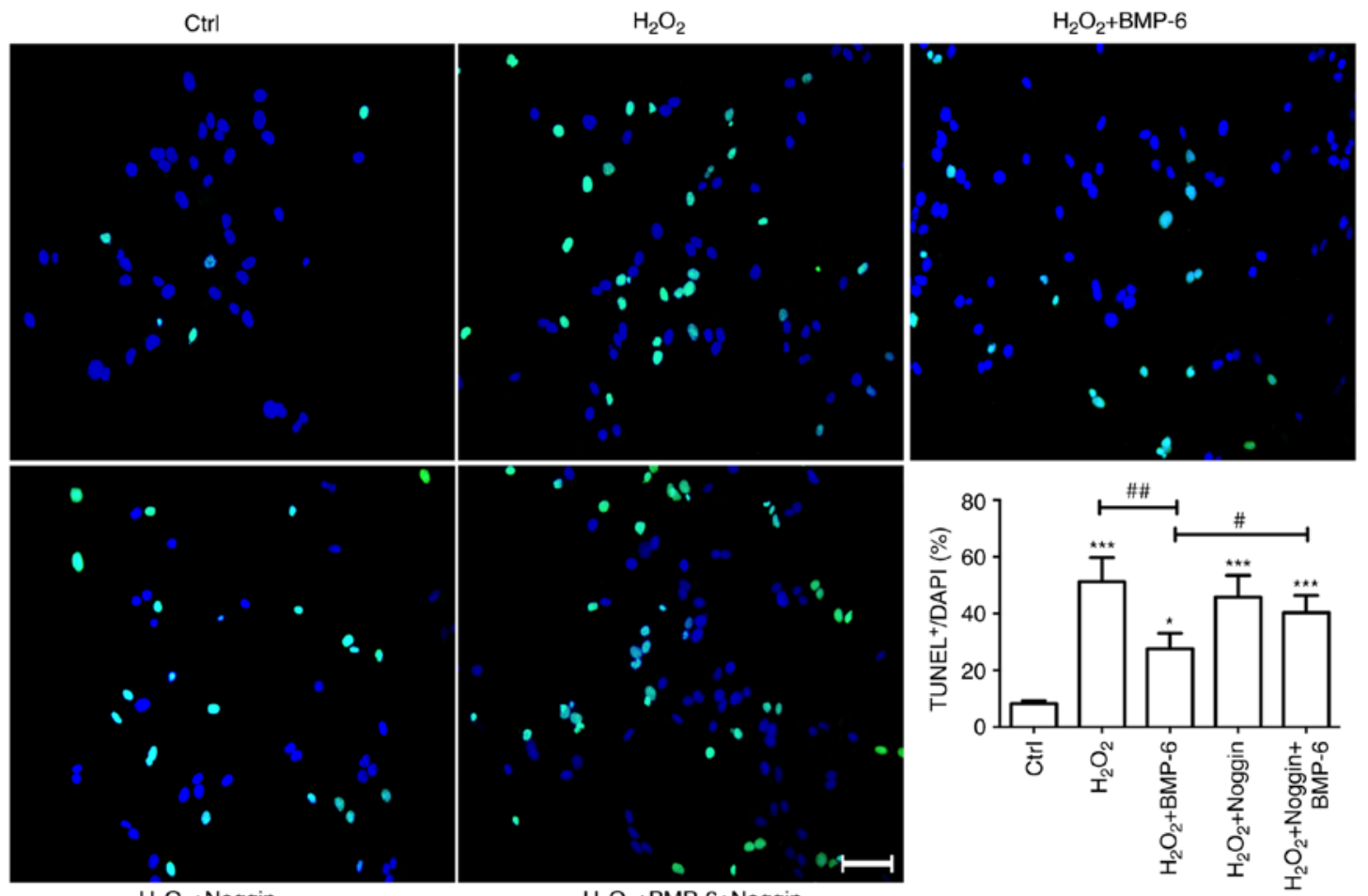

Figure 4. Effects of BMP-6 pretreatment on apoptosis of RPE cells induced by $\mathrm{H}_{2} \mathrm{O}_{2}$-mediated oxidative stress injury. Adherently cultured RPE cells were treated with normal saline $(\mathrm{Ctrl}), \mathrm{H}_{2} \mathrm{O}_{2}(30 \mu \mathrm{M})$, BMP-6 $(100 \mathrm{ng} / \mathrm{ml})$ or noggin $(3 \mu \mathrm{g} / \mathrm{ml})+\mathrm{BMP}-6(100 \mathrm{ng} / \mathrm{ml})$. Subsequently, the cells were treated with $\mathrm{H}_{2} \mathrm{O}_{2}$ $(200 \mu \mathrm{M})$ for $6 \mathrm{~h}$. Subsequently, TUNEL staining was performed to examine apoptosis. Green staining indicates TUNEL-positive cells, whereas nuclei labeled with DAPI display bright blue fluorescence (magnification, $\mathrm{x} 40$ ). Scale bar, $50 \mu \mathrm{m}$. The number of TUNEL-stained cells was statistically analyzed. * $\mathrm{P}<0.05$ and ${ }^{* * *} \mathrm{P}<0.001$ vs. the Ctrl group. ${ }^{\#} \mathrm{P}<0.01$ vs. the $\mathrm{H}_{2} \mathrm{O}_{2}+\mathrm{BMP}-6$ group. ${ }^{\# \prime} \mathrm{P}<0.01$ vs. cells exposed to $200 \mu \mathrm{M} \mathrm{H}_{2} \mathrm{O}_{2}$ only. BMP-6, bone morphogenetic protein 6 ; Ctrl, control; $\mathrm{H}_{2} \mathrm{O}_{2}$, hydrogen peroxide; RPE, retinal pigment epithelial; TUNEL, terminal deoxynucleotidyl transferase dUTP nick-end labeling.

the group treated with $\mathrm{H}_{2} \mathrm{O}_{2}$ only, SB203580 and SP600125 reduced pro-caspase-3 expression (Fig. 6A and B), and the number of TUNEL-positive cells (Fig. 6C). Based on these results, BMP- 6 may protect RPE cells from $\mathrm{H}_{2} \mathrm{O}_{2}$-induced oxidative stress injury by inhibiting p38 and JNK signaling.

\section{Discussion}

To the best of our knowledge, the present study is the first to report that BMP-6 expression was markedly decreased in the aqueous humors of patients with nAMD. BMPs are a group of highly conserved functional proteins with similar structures that were originally identified to induce bone and cartilage formation in vivo. In particular, BMPs are widely distributed in various human tissues and cells, where they regulate the growth, differentiation and apoptosis of target cells, and consequently serve important roles in numerous processes, including embryonic growth and development, wound healing, and tumor development and progression (11). BMP-6 has unique structural and functional characteristics, and its function is fairly complex. It participates in the regulation of various metabolic processes in vivo. Notably, BMP-6 not only has an important role in the maintenance of physiological functions, but also mediates the occurrence of many diseases (12). RPE cells express BMP-6, and oxidative stress downregulates BMP-6 (13). In addition, BMP-6 expression is markedly decreased in RPE cells isolated from the eyes of cadavers with early macular degeneration (14). These results indicated that BMP-6 may have a key role in the development of AMD.
To the best of our knowledge, the present study was also the first to demonstrate that BMP- 6 protected human RPE cells from oxidative stress injury, as reflected by a decrease in the numbers of TUNEL-positive cells, a reduction in the expression of the apoptotic signaling protein pro-caspase-3, and an increase in the $\mathrm{Bcl}-2 / \mathrm{Bax}$ ratio. Further investigations revealed that BMP-6 inhibited the $\mathrm{H}_{2} \mathrm{O}_{2}$-induced increases in p-JNK and p-p38 expression, and that inhibition of JNK and p38 activation protected RPE cells from oxidative stress injury. These findings suggested that BMP- 6 may protect RPE cells by inhibiting activation of JNK and p38 signaling.

At present, the pathogenesis of AMD remains unclear; however, it has been hypothesized to be associated with oxidative stress and inflammation. Due to high oxygen consumption, richness in polyunsaturated fatty acids and exposure to light, retinal tissues are highly susceptible to oxidative stress (15). $\mathrm{H}_{2} \mathrm{O}_{2}$ is an important reactive oxygen species (ROS), and exogenous $\mathrm{H}_{2} \mathrm{O}_{2}$ easily penetrates the cell membrane and enters the cell. If transition metals are present in the cell, $\mathrm{H}_{2} \mathrm{O}_{2}$ is converted to highly reactive free radicals via the Fenton reaction, and the resultant free radicals, including singlet oxygen and hydroxyl free radicals, cause additional cellular damage. Since $\mathrm{H}_{2} \mathrm{O}_{2}$ can rapidly penetrate the cell membrane, it is considered a good experimental model to explore oxidative stress-induced cell injury (16). Among all of the cell types in the retina, RPE cells are the most prone to oxidative stress injury due to their anatomical location proximal to the choroid (17). In the present study, $\mathrm{H}_{2} \mathrm{O}_{2}$ was used to produce ROS, which damage RPE cells. 

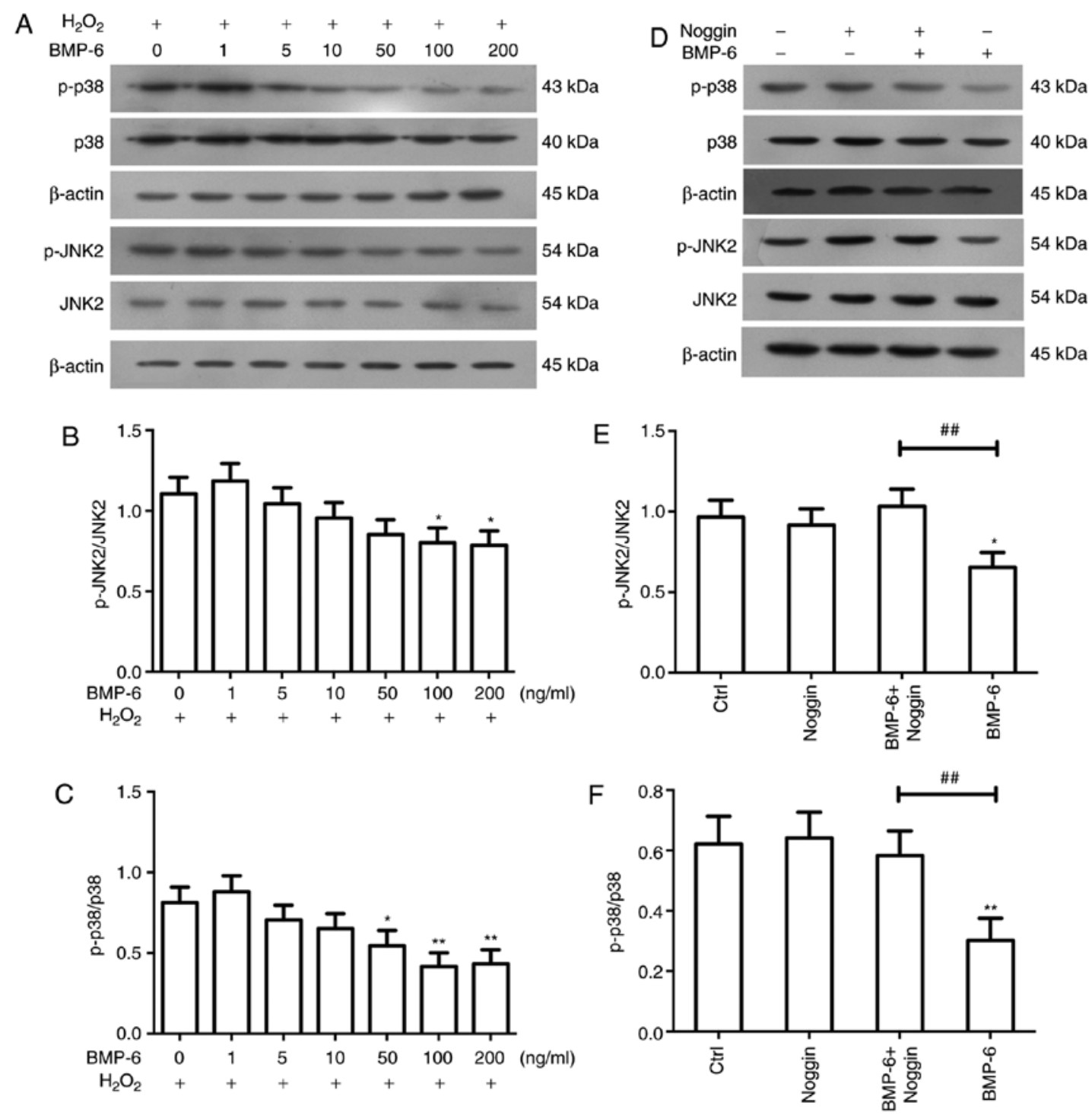

Figure 5. Effects of BMP-6 on JNK and p38 signaling in RPE cells following $\mathrm{H}_{2} \mathrm{O}_{2}$-mediated oxidative stress injury. RPE cells were pretreated with various BMP- 6 concentrations and were then treated with $200 \mu \mathrm{M} \mathrm{H}_{2} \mathrm{O}_{2}$ for $6 \mathrm{~h}$. (A) Subsequently, western blotting was used to determine the expression levels of p-p38, p38, p-JNK and JNK2. $\beta$-actin was used as an internal reference. (B and C) Alterations in the ratios of p-p38/p38 and p-JNK2/JNK2 were determined. Data are presented as the means \pm standard deviation. ${ }^{*} \mathrm{P}<0.05$ and ${ }^{* *} \mathrm{P}<0.01$ vs. cells exposed to $200 \mu \mathrm{M} \mathrm{H} \mathrm{H}_{2} \mathrm{O}_{2}$ only. (D) RPE cells were pretreated with the BMP-6 inhibitor noggin and were then treated with BMP-6. Western blotting was used to detect the expression levels of p-p38, p38, p-JNK and JNK2. $\beta$-actin was used as an internal reference. (E and F) Alterations in the ratios of p-p38/p38 and p-JNK2/JNK2 were determined. Data are presented as the means \pm standard deviation. ${ }^{*} \mathrm{P}<0.05$ and ${ }^{* *} \mathrm{P}<0.01$ vs. the Ctrl group. ${ }^{\# \#} \mathrm{P}<0.01$, vs. the BMP-6-treated group. BMP-6, bone morphogenetic protein 6; Ctrl, control; $\mathrm{H}_{2} \mathrm{O}_{2}$, hydrogen peroxide; JNK2, c-Jun N-terminal protein kinase 2; p-, phosphorylated; RPE, retinal pigment epithelial.

$\mathrm{H}_{2} \mathrm{O}_{2}$ not only reduced cell viability, but also induced apoptosis. These findings are consistent with the results of a previous study (18).

$\mathrm{H}_{2} \mathrm{O}_{2}$-mediated apoptosis is a mixed response involving numerous apoptotic pathways, which includes activation of the caspase pathways and dysregulation of the $\mathrm{Bcl}-2 / \mathrm{Bax}$ balance $(19,20)$. Caspase-3 is a key regulatory protein in the caspase-dependent apoptotic pathway $(21,22)$, which can be activated by caspase-8/9. Caspase family proteases are downstream targets of Bax and Bcl-2 in the mitochondrial apoptosis signaling pathway $(23,24)$. Mitochondrial membrane destruction not only downregulates the expression of the apoptosis inhibitor Bcl-2, but also results in the accumulation of Bax and the formation of Bax oligomers. Notably, Bax mediates apoptosis $(25,26)$. In the present study, $\mathrm{H}_{2} \mathrm{O}_{2}$ stimulation decreased procaspase- 3 and Bcl-2 levels, and increased Bax expression levels. These results indicated that these apoptotic signaling proteins may mediate oxidative stress injury-induced apoptosis of RPE cells, which is consistent with the findings of previous studies $(27,28)$. Furthermore, the present study revealed that BMP-6 reversed the $\mathrm{H}_{2} \mathrm{O}_{2}$-induced reduction of pro-caspase- 3 , and maintained the balance between $\mathrm{Bcl}-2$ and $\mathrm{Bax}$ in vitro. Therefore, BMP- 6 may protect RPE cells from $\mathrm{H}_{2} \mathrm{O}_{2}$-mediated oxidative stress injury.

As key regulatory factors in intracellular signaling, JNK and p38 MAPK participate in the regulation of numerous stress responses, including ionizing radiation, the inflammatory response, ischemia and hemorrhage $(29,30)$. Previous studies have reported that JNK and p38 activation are associated with oxidative stress-induced cell death in various cell 

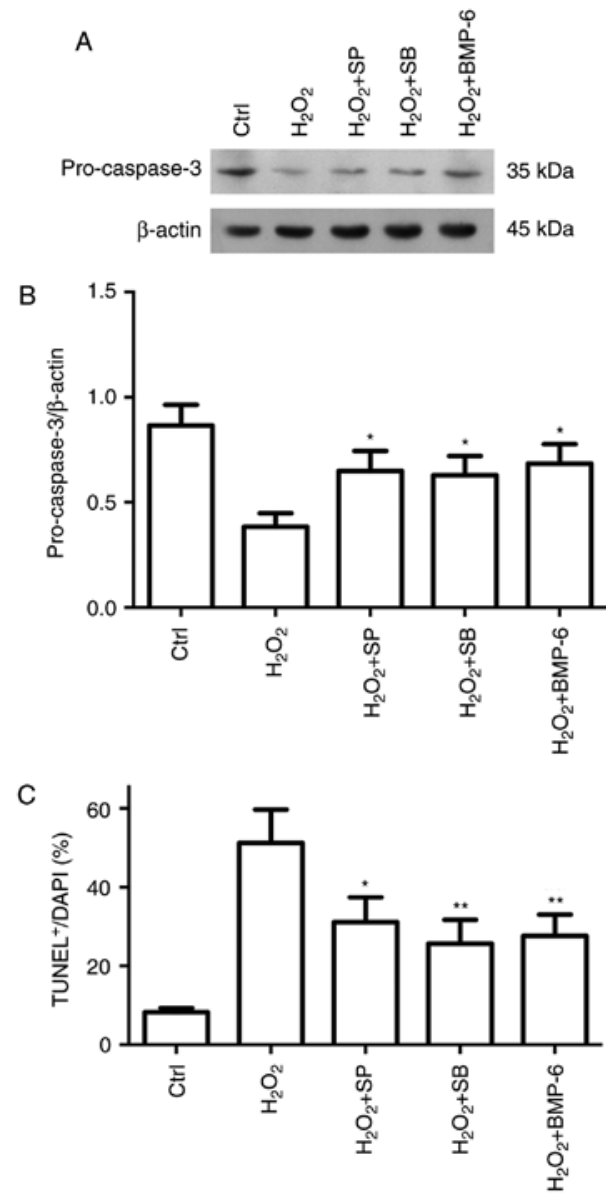

Figure 6. Protective effect of BMP-6 on $\mathrm{H}_{2} \mathrm{O}_{2}$-induced RPE cell apoptosis is involved in the inactivation of JNK and p38 MAPK pathways. Adherently cultured RPE cells were treated with normal saline (Ctrl), $\mathrm{H}_{2} \mathrm{O}_{2}(200 \mu \mathrm{M})$, $\mathrm{SB}+\mathrm{H}_{2} \mathrm{O}_{2}, \mathrm{SP}+\mathrm{H}_{2} \mathrm{O}_{2}$ or BMP- $6+\mathrm{H}_{2} \mathrm{O}_{2}$. After $6 \mathrm{~h}$ of treatment, western blotting was performed. (A and $\mathrm{B}$ ) Pro-caspase-3 protein expression was determined by western blotting and was normalized to $\beta$-actin. (C) Apoptosis was examined by TUNEL staining, and the results were statistically analyzed ${ }^{*} \mathrm{P}<0.05$ and ${ }^{* *} \mathrm{P}<0.01$ vs. cells exposed to $200 \mu \mathrm{M} \mathrm{H}_{2} \mathrm{O}_{2}$ only. BMP-6, bone morphogenetic protein 6; Ctrl, control; $\mathrm{H}_{2} \mathrm{O}_{2}$, hydrogen peroxide; RPE, retinal pigment epithelial; SB, SB203580; SP, SP600125; TUNEL, terminal deoxynucleotidyl transferase dUTP nick-end labeling.

types, including RPE cells $(9,10)$. The present study revealed that oxidative stress injury induced apoptosis. Notably, $\mathrm{H}_{2} \mathrm{O}_{2}$ activated JNK and p38, which triggered the caspase cascade and eventually led to cell death. Previous studies have reported that inhibiting JNK and p38 activation protects cells against oxidative stress injury $(31,32)$. In the present study, BMP- 6 inhibited activation of the JNK and p38 pathways. Noggin is a specific inhibitor of BMP-6 $(33,34)$; treatment with noggin inhibited the effects of BMP-6 on JNK and p38 in the present study. Although possible synergy between these pathways upon oxidative stress-induced injury was not examined in this study, a large number of studies demonstrated that injuries may simultaneously activate the JNK and p38 pathways $(35,36)$. The present study revealed that BMP- 6 not only inhibited the $\mathrm{H}_{2} \mathrm{O}_{2}$-induced activation of JNK and p38 MAPK signaling pathways in vitro, but also inhibited caspase- 3 activation and reduced apoptosis. These results indicated that BMP- 6 may protect RPE cells by inhibiting JNK and p38 activity.
Overall, the present study demonstrated that BMP-6 attenuated $\mathrm{H}_{2} \mathrm{O}_{2}$-induced oxidative damage in human RPE cells, as evidenced by changes in cell viability, apoptosis, caspase-3 activity and MAPK signaling. In addition, the present study suggested that the protective effects of BMP- 6 were mediated by inhibition of the JNK/p38 signaling pathways, and subsequent suppression of caspase- 3 activity. Furthermore, BMP-6 dysregulated the Bcl-2/Bax balance, thereby inhibiting apoptosis of RPE cells. Although these findings suggested that BMP-6 may protect RPE cells from oxidative stress injury by regulating $\mathrm{JNK} / \mathrm{p} 38$ phosphorylation, this conclusion is based on in vitro experiments.

The present study was also subject to other limitations. Ki et al reported that pathways involving JNK and p38 MAPK, but not extracellular signal-regulated kinase (ERK) $1 / 2$, mediated apoptosis and were involved in the inflammatory response (9). The present study did not observe alterations in ERK signaling. ERK1/2 and p38 MAPK are generally phosphorylated together in response to numerous types of stress, including transforming growth factor- $\beta$, oxidative and inflammatory stress. We aim to further analyze this in the future. Zhang et al reported that numerous types of BMP receptor (BMPR), including BMPR1A, BMPR1B and BMPR2, were expressed in the retina and choroid (37). Hemojuvelin (HJV) is an iron-regulatory protein and a BMP coreceptor; $\mathrm{HJV}^{-/-}$mice have been reported to accumulate excess iron in the retina, and exhibit aberrant vascularization and retinal hemangiomas (38). BMP-6 binds to BMP receptor type I (BMPRI) and BMPRII cell surface receptors, and to the coreceptor HJV (39). Arjunan et al revealed that G-protein-coupled receptor 91 is a target of BMP-6 and HJV deletion enhances BMP signaling in the retina (40). Further studies should investigate the BMP-6 receptor and the BMP-6-mediated signaling pathways, including HJV receptor and protein kinase $\mathrm{B}$ pathways. In addition, the protective effects of BMP-6 on RPE cells require further exploration in vivo.

In conclusion, the present study demonstrated that BMP-6 may protect RPE cells from oxidative stress injury to a certain extent, which may be associated with alterations in the MAPK signaling pathway. This study may prove useful for the development of more effective therapies to prevent the development of nAMD.

\section{Acknowledgements}

Not applicable.

\section{Funding}

The present study was supported by grants from the Science and Technology Development Project of Shaanxi Province (grant nos. 2012K16-11-01 and 2016SF-257) and the China postdoctoral science foundation (grant no. 2017M623152).

\section{Availability of data and materials}

The datasets used and/or analyzed during the current study are available from the corresponding author on reasonable request. 


\section{Authors' contributions}

LC and YoL conceived and designed the study. LC, YaL, YiL, ZZ and BM performed the experiments. ML and XL collected the patient data and conducted the statistical analysis. LC and ML wrote the study. LC, ZZ and YoL reviewed and edited the manuscript. All authors read and approved the final manuscript.

\section{Ethics approval and consent to participate}

The protocol for this research project was approved by the Ethics Committee of the First Affiliated Hospital of Xi'an Jiao-tong University, Xi'an, Shaanxi, China, and patients provided written informed consent.

\section{Consent for publication}

Patients provided written informed consent.

\section{Competing interests}

The authors declare that they have no competing interests.

\section{References}

1. Klettner A: Age-related macular degeneration-biology and treatment. Med Monatsschr Pharm 38: 258-66, 2015 (In German).

2. Liu C, Cao L, Yang S, Xu L, Liu P, Wang F and Xu D: Subretinal injection of amyloid- $\beta$ peptide accelerates RPE cell senescence and retinal degeneration. Int J Mol Med 35: 169-76, 2015.

3. Zhu Y, Zhang L, Lu Q, Gao Y, Cai Y, Sui A, Su T, Shen X and Xie B: Identification of different macrophage subpopulations with distinct activities in a mouse model of oxygen-induced retinopathy. Int J Mol Med 40: 281-292, 2017.

4. Hadziahmetovic M, Song Y, Wolkow N, Iacovelli J, Kautz J, Roth MP and Dunaief JL: Bmp6 regulates retinal iron homeostasis and has altered expression in age-related macular degeneration. Am J Pathol 179: 335-348, 2011.

5. Andriopoulos B Jr, Corradini E, Xia Y, Faasse SA, Chen S, Grgurevic L, Knutson MD, Pietrangelo A, Vukicevic S, Lin HY and Babitt JL: BMP6 is a key endogenous regulator of hepcidin expression and iron metabolism. Nat Genet 41: 482-487, 2009.

6. Haynes T, Gutierrez C, Aycinena JC, Tsonis PA and Del Rio-Tsonis K: BMP signaling mediates stem/progenitor cell-induced retina regeneration. Proc Natl Acad Sci USA 104: 20380-20385, 2007.

7. Canali S, Zumbrennen-Bullough KB, Core AB, Wang CY, Nairz M, Boulery R, Swirski FK and Babbit JL: Endothelial cells produce bone morphogenetic protein 6 required for iron homeostasis in mice. Blood 129: 405-414, 2017.

8. McCubrey JA, Lahair MM and Franklin RA: Reactive oxygen species-induced activation of the MAP kinase signaling pathways. Antioxid Redox Signal 8: 1775-1789, 2006.

9. Ki YW, Park JH, Lee JE, Shin IC and Koh HC: JNK and p38 MAPK regulate oxidative stress and the inflammatory response in chlorpyrifos-induced apoptosis. Toxicol Lett 218: 235-245, 2013.

10. Feligioni M, Brambilla E, Camassa A, Sclip A, Arnaboldi A, Morelli F, Antoniou X and Borsello T: Crosstalk between JNK and SUMO signaling pathways: deSUMOylation is protective against $\mathrm{H}_{2} \mathrm{O}_{2}$-induced cell injury. PLoS One 6: e28185, 2011.

11. Shepherd TG, Heriault BL and Naehtigal MW: Autocrine BMP4 signalling regulates ID3 Proto-oncogene expression in human ovarian cancer cells. Gene 414: 95-105, 2008.

12. Piubelli C, Castagna A, Marchi G, Rizzi M, Busti F, Badar S, Marchetti M, De Gobbi M, Roetto A, Xumerle L, et al: Identification of new BMP6 pro-peptide mutations in patients with iron overload. Am J Hematol 92: 562-568, 2017.
13. Yan J, Yang S, Zhang J, Zhai $\mathrm{C}$ and Zhu T: BMP6 attenuates oxidant injury in HK-2 cells via Smad-dependent HO-1 induction. Free Radic Biol Med 46: 1275-1282, 2009.

14. Meynard D, Kautz L, Darnaud V, Canonne-Hergaux F, Coppin H and Roth MP: Lack of the bone morphogenetic protein BMP6 induces massive iron overload. Nat Genet 41: 478-481, 2009.

15. Bhuto I and Luty G: Understanding age-related macular degeneration (AMD): Relationships between the photoreceptor/retinal pigment epithelium/Bruch's membrane/choriocapillaris complex. Mol Aspects Med 33: 295-317, 2012.

16. Haudek VJ, Gundacker NC, Slany A, Wimmersion H, Bayer E, Pablé K and Gerner C: Consequences of acute and chronic oxidative stress upon the expression pattern of proteins in peripheral blood mononuclear cells. J Proteome Res 7: 5138-5147, 2008.

17. Zhao L, Li Y, Song D, Song Y, Theurl M, Wang C, Cwanger A, Su G and Dunaief JL: A high serum iron level causes mouse retinal iron accumulation despite an intact blood-retinal barrier. Am J Pathol 184: 2862-2867, 2014.

18. Tu G, Zhang YF, Wei W, Li L, Zhang Y, Yang J and Xing Y: Allicin attenuates $\mathrm{H}_{2} \mathrm{O}_{2}$-induced cytotoxicity in retinal pigmented epithelial cells by regulating the levels of reactive oxygen species. Mol Med Rep 13: 2320-2326, 2016.

19. Cia D, Vergaud-Gauduchon J, Jacquemot $\mathrm{N}$ and Doly $\mathrm{M}$ : Epigallocatechin gallate (EGCG) prevents $\mathrm{H}_{2} \mathrm{O}_{2}$-induced oxidative stress in primary rat retinal pigment epithelial cells. Curr Eye Res 39: 944-952, 2014.

20. Tamm C, Zhivotovsky B and Ceccatelli S: Caspase-2 activation in neural stem cells undergoing oxidative stress-induced apoptosis. Apoptosis 13: 354-363, 2008.

21. Savory J, Rao JK, Huang Y, Letada PR and Herman MM: Age-related hippocampal changes in Bcl-2: Bax ratio, oxidative stress, redox-active iron and apoptosis associated with aluminum-induced neurodegenerati: Increased susceptibility with aging. Neurotoxicology 20: 805-817, 1999.

22. Naderi J, Hung $M$ and Pandey S: Oxidative stress-induced apoptosis in dividing fibroblasts involves activation of p38 MAP kinase and over-expression of Bax: Resistance of quiescent cells to oxidative stress. Apoptosis 8: 91-100, 2003.

23. Snigdha S, Smith ED, Prieto GA and Cotman CW: Caspase-3 activation as a bifurcation point between plasticity and cell death. Neurosci Bull 28: 14-24, 2012.

24. Hoshyar R, Bathaie SZ and Sadeghizadeh M: Crocin triggers the apoptosis through increasing the $\mathrm{Bax} / \mathrm{Bcl}-2$ ratio and caspase activation in human gastric adenocarcinoma, AGS, cells. DNA Cell Biol 32: 50-57, 2013.

25. Rosen RB, Hu DN, Chen M, McCormick SA, Walsh J and Roberts JE: Effects of melatonin and its receptor antagonist on retinal pigment epithelial cells against hydrogen peroxide damage. Mol Vis 18: 1640-1648, 2012.

26. Wang ZY, Shen LJ, Tu L, Hu DN, Liu GY, Zhou ZL, Lin Y, Chen LH and Qu J: Erythropoietin protects retinal pigment epithelial cells from oxidative damage. Free Radical Biol Med 46: 1032-1041, 2009.

27. Paeng SH, Jung WK, Park WS, Lee DS, Kim GY, Choi YH, Seo SK, Jang WH, Choi JS, Lee YM, et al: Caffeic acid phenethyl ester reduces the secretion of vascular endothelial growth factor through the inhibition of the ROS, PI3K and HIF-1 $\alpha$ signaling pathways in human retinal pigment epithelial cells under hypoxic conditions. Int J Mol Med 35: 1419-1426, 2015.

28. Bokara KK, Kwon KH, Nho Y, Lee WT, Park KA and Lee JE: Retroviral expression of arginine decarboxylase attenuates oxidative burden in mouse cortical neural stem cells. Stem Cells Dev 20: 527-537, 2011.

29. Sekine Y, Takeda K and Ichijo H: The ASK1-MAP kinase signaling in ER stress and neurodegenerative diseases. Curr Mol Med 6: 87-97, 2006.

30. Kamata H, Honda S, Maeda S, Chang L, Hirata H and Karin M: Reactive oxygen species promote TNFalpha-induced death and sustained JNK activation by inhibiting MAP kinase phosphatases. Cell 120: 649-661, 2005.

31. Kim JH, Choi W, Lee JH, Jeon SJ, Choi YH, Kim BW, Chang HI and Nam SW: Astaxanthin inhibits $\mathrm{H}_{2} \mathrm{O}_{2}$-mediated apoptotic cell death in mouse neural progenitor cells via modulation of P38 and MEK signaling pathways. J Microbiol Biotechnol 19: 1355-1363, 2009.

32. Wang C, Hao Z, Zhou J, Zhang J, Sun Y and Liang C: Rutaecarpine alleviates renal ischemia reperfusion injury in rats by suppressing the JNK/p38 MAPK signaling pathway and interfering with the oxidative stress response. Mol Med Rep 16: 922-928, 2017. 
33. Yuen HF, McCrudden CM, Grills C, Zhang SD, Huang YH, Chan KK, Chan YP, Wong ML, Law S, Srivastava G, et al: Combinatorial use of bone morphogenetic protein 6 , noggin and SOST significantly predicts cancer progression. Cancer Sci 103 . 1145-1154, 2012.

34. Song K, Krause C, Shi S, Patterson M, Suto R, Grgurevic L, Vukicevic S, van Dinther M, Falb D, Ten Dijke P and Alaoui-Ismaili MH: Identification of a key residue mediating bone morphogenetic protein (BMP)-6 resistance to noggin inhibition allows for engineered BMPs with superior agonist activity. J Biol Chem 285: 12169-12180, 2010.

35. Abell AN, Granger DA and Johnson GL: MEKK4 stimulation of p38 and JNK activity is negatively regulated by GSK3beta. J Biol Chem 282: 30476-30484, 2007.

36. Sun G, Li Z, Wang X, Tang W and Wei Y: Modulation of MAPK and Akt signaling pathways in proximal segment of injured sciatic nerves. Neurosci Lett 534: 205-210, 2013.

37. Zhang Y, Liu Y, Hang A, Phan E and Wildsoet CF: Differential gene expression of BMP2 and BMP receptors in chick retina \& choroid induced by imposed optical defocus. Vis Neurosci 33 E015, 2016.
38. Tawfik A, Gnana-Prakasam JP, Smith SB and Ganapathy V: Deletion of hemojuvelin, an iron-regulatory protein, in mice results in abnormal angiogenesis and vasculogenesis in retina along with reactive gliosis. Invest Ophthalmol Vis Sci 55: 3616-3625, 2014.

39. Bandyopadhyay A, Yadav PS and Prashar P: BMP signaling in development and diseases: A pharmacological perspective. Biochem Pharmacol 85: 857-864, 2013.

40. Arjunan P, Gnanaprakasam JP, Ananth S, Romej MA, Rajalakshmi VK, Prasad PD, Martin PM, Gurusamy M, Thangaraju M, Bhutia YD and Ganapathy V: Increased retinal expression of the pro-angiogenic receptor GPR91 via BMP6 in a mouse model of juvenile hemochromatosis. Invest Ophthalmol Vis Sci 57: 1612-1619, 2016. 